\title{
Parents of children with haemophilia - a transforming experience
}

Karen Beeton ${ }^{\star}$, David Neal+, Professor Tim Watson*, Professor Christine Lee ${ }^{\wedge}$

*School of Health and Emergency Professions

University of Hertfordshire

College Lane

Hatfield

Herts AL10 9AB

+ School of Health and Social Care

University of Hertfordshire

College Lane

Hatfield

Herts AL10 9AB

^Haemophilia Centre

Royal Free NHS Trust

Pond Street

Hampstead

London NW3 2QG

Contact details for further correspondence

Karen Beeton

Email k.s.beeton@herts.ac.uk

Telephone 01707284114

Fax 01707284977 


\section{Summary}

Due to the improvements in the management of haemophilia, children with severe haemophilia in the United Kingdom have very different experiences of their condition compared to many adults' early experiences of haemophilia. However haemophilia can still have physical and social effects which can impact on QoL not only for a child who has the condition but also for their parents. The purpose of this study was to undertake a qualitative exploration of the impact of haemophilia on parents. The participants included 12 parents of children with severe haemophilia who took part in interviews or focus groups. Four major themes emerged from the data which were initial experiences, managing the condition, engaging with others and developing mastery. The findings highlighted the importance of evaluating parents' experiences. Parents are deeply affected by their child's condition and their lives are transformed by the experiences of living with a child with haemophilia. Parents' responses are influenced by how well the child is managing their disorder and the difficulties they are experiencing. Further studies are required in order to develop a more complete understanding of the impact of haemophilia on parent's lives.

\section{Key words}

Haemophilia, parents, quality of life, qualitative research 


\section{Introduction}

In the present health climate children with severe haemophilia in the United Kingdom (UK) have very different experiences of their condition compared to many adults' early experiences of haemophilia. The ready availability of factor replacement and the widespread use of prophylaxis have ensured that children can be more active and severe bleeds occur less frequently. Consequently children do not usually develop the marked impairments and disability that have occurred in the past. Moreover, the use of more purified products has ensured that children have not developed infections such as Human Immunodeficiency Virus (HIV) and hepatitis which have had such a devastating impact on the adult population. However despite these improvements in medical care, children with haemophilia do still experience bleeds and parents and their children still have to manage haemophilia, recognise the onset of bleeds and learn to administer factor replacement. There may still be limitations to participation in more vigorous activities and sports, particularly at a competitive level (Buzzard, 1996). The implications of not having any impairments and feeling able to participate in more energetic pursuits but having restrictions imposed (Schoenmakers et al., 2001) affects not only the children themselves but also the wider family network particularly the parents. Parents also have to make decisions about who to inform about their child's haemophilia.

There has been considerable emphasis focused on the evaluation of the impact of haemophilia on quality of life (QoL) in adults and recently haemophilic specific tools to evaluate QoL in children have been constructed (Bullinger et al., 2002, MancoJohnson et al., 2004, Young et al., 2004). In contrast there has been relatively little research directed to the impact of haemophilia on parents of children with haemophilia. This would seem to be an important area to address as there is some evidence to suggest that parents may be more concerned and more distressed than those who actually have haemophilia (Agle et al., 1987). Although coping processes have been assessed in a number of studies (Salk et al., 1972, Miller et al., 2000, Canclini et al., 2003) the parents' views of QoL have only recently begun to be considered (Bullinger et al., 2003). In addition, the parents' response to living with a haemophilic child may also provide an important foundation for the behaviour and perceptions of the child towards their condition (Canclini et al., 2003).

This paper presents findings from part of a larger qualitative study exploring the impact of haemophilia on QoL for adults and parents. It was envisaged that adopting a qualitative approach would provide a deeper understanding of how parents 
manage their child's haemophilia and how their life is affected by haemophilia. The aim of this part of the study was to explore the question 'how does haemophilia impact on parents' QoL?'

\section{Method}

Prior to the commencement of the study, ethical approval was granted by the Royal Free NHS Trust Ethics Committee. Forty one couples or single mothers of children under 16 years were invited by letter to participate in either a focus group or interview. The main advantage of a focus group is the ability of the participants to share experiences which can promote the collection of rich data (Rice and Ezzy, 1999). However, it is also recognised that some individuals prefer the anonymity of an individual interview so both methods of data collection were offered to the participants.

Three couples, five mothers and one father agreed to participate, a total of 12 parents $(\mathrm{N}=12)$. Three of the mothers were known to be carriers. Four mothers and two fathers from different families opted to attend a focus group plus one partner who was not related to the child. The focus group met on four separate occasions over a two year period and involved the same parents (although not all the parents attended every meeting). This prolonged involvement was predominantly due to the value of the shared discussions identified by the participants and their willingness to attend follow up sessions. The focus group participants had seven children between them, with one mother having two sons. Five of the children had Haemophilia A, two had Haemophilia $B$, one of whom had a high titre inhibitor. Their ages ranged from 3-10 years.

Two couples and one mother had individual interviews. Their children were aged between 18 months and 13 years. One couple had two teenage boys, both with Haemophilia B.

All of the children of these parents were on prophylaxis except the youngest child who attended the haemophilia centre for treatment of bleeds and one child who had an inhibitor. The child with an inhibitor was reported to experience frequent bleeding episodes and have visible signs of impairment.

All the focus groups and the interviews took place in the haemophilia centre except one interview that took place in the interviewee's own home. All of the discussions 
were tape recorded with the participants' permission. After a general introduction the opening question asked, 'how does haemophilia impact on your QoL?' The parents considered the question from their own perspective and the impact of haemophilia on their child and the family. The participants were free to explore issues relevant to them. The interviews and focus groups each lasted approximately 2 hours. The tapes were then transcribed and the transcripts returned to the participants for verification and any amendments or additional comments.

The data analysis began by reading the transcripts on several occasions in order for the researcher to become familiar with and immersed in the data. A structured and detailed process of data analysis was then undertaken using a computer program, NVivo (version 1.3). There has been increasing use of computer programs to assist in the analysis of qualitative data in recent years as they can help to organise large amounts of free text (Crowley et al, 2002). The transcripts were imported into NVivo and the data analysed using the 'code and retrieve' method. Sentences and phrases were coded (labelled) according to their meaning and then all the data with the same code was collated (retrieve) (Richard and Richards, 1998). Once all the data had been coded, the codes were reviewed and then grouped together into related topics through an interpretative process, into four main themes. These four themes were entitled initial experiences, managing the condition, engaging with others and mastery.

\section{Results}

Due to the age of the children in this study, from 18 months to 13 years, the parents' experience over their child's trajectory from birth to teenage years was examined. It is recognised however that the parents' experiences are an iterative process which may follow different pathways depending on personal circumstances. In order to identify the different participants but preserve confidentiality, each parent in the study was given a number and quotes are attributed to either a focus group participant, FG1, 2, 3 etc. or interview participant 1,2,3 and $m$ (male) or $f$ (female) to denote the gender of the participant.

\section{Initial experiences}

This theme consisted of two sub themes, finding out about the diagnosis and the very young child's early years. 


\section{Finding out about the diagnosis}

For all the parents involved in this study, finding out that their child had severe haemophilia was a huge emotional shock which caused grief, guilt and loss of self esteem. This was apparent regardless of whether the mother knew she was a carrier and had the prospect that she may have a haemophilic child. These parents experienced a significant life event analogous to a biographical disruption, as described by Bury (1982). As one mother said:

FG(5f): It was quite shocking, for about three years my life changed completely.

The identification of the diagnosis was usually precipitated by the child having a fall or injury and experiencing a response that was more marked than would have normally been expected or that was slow to resolve. Widespread bruising can be common in children with haemophilia and prior to the diagnosis this could lead to concerns that the child was experiencing non accidental injuries which compounded the parents' distress. Even if a parent was expecting to be questioned about this, it was still a shock:

$F G(1 \mathrm{~m})$ : We took him (to the hospital), the paediatrician was called down from a ward, they had never seen anything like it, bruises ... I was waiting for the question 'Do you knock him about?'. It was quite shocking to be asked the question even though I was expecting it.

The way the diagnosis was divulged could add to the emotional trauma. Information provided by health care professionals at non specialist hospitals was sometimes inaccurate. One couple was told that their child would develop arthritis and need a wheelchair in the future:

Int(2m): No they didn't tell us right. As soon as we got here (the haemophilia centre) they could see on our faces we were in despair.

Once the child had been diagnosed, the parents then had to learn how to recognise the clinical manifestations of haemophilia and manage it effectively. This caused many challenges for parents.

\section{The very young child's early years}

Managing haemophilia in very young children was generally regarded as the most stressful period for the parents. This was mainly due to the uncertainty caused by the unpredictability of bleeds and the lack of experience of the condition. Parents had to 
learn about the disorder, how to recognise bleeds and try to avoid bleeds occurring if possible.

The parents had to make decisions about appropriate management if the child fell or knocked themselves or if the child had a bleed. This decision-making process was made more difficult by the uncertainty over whether a bleed had occurred, if it was going to get worse and if the child needed factor replacement. If parents adopted a 'wait and see' policy, this could engender more anxiety:

Int(2m): One of the worst bits for me is not so much we have got to take him to hospital ... it is that in between ... is it going to flare up in the night?

As these parents had little practical experience to draw on, and very small children and babies could not explain their symptoms, this added to the uncertainty. This was also amplified by the variable response to trauma. Small children frequently fall over and sometimes a bleed did not occur and at other times a large bleed would occur, possibly hours later. As a result, parents were living with constant worries in these early years:

Int(3f): It is such a scary journey those first few years, you are not sure what you are meant to do ... so many worries and bits of information.

Parents managed this uncertainty by being very protective of the child and tended to be vigilant in monitoring their child and his activities. Parents recognised that they were often more protective than other family members and friends were with their children. If parents went to an unfamiliar place, they would take time to find out about hazards and potential areas where injury could occur. They were always prepared for any emergency.

If the child needed factor replacement, parents had to attend a haemophilia centre. Very young children's veins are commonly difficult to access and require specialist medical intervention. If a problem occurred at night, parents often had to attend local emergency departments. As one mother said:

FG(2f): You didn't have doctors and nurses like this here who knew about it........ every six months you get a change of doctor ... (we) would arrive at 3 o'clock in the morning, the doctor slumped over the desk, nobody has got the treatment, they would lose his notes ... it hasn't been a pleasant journey to this point. 
The difficulties experienced in trying to administer factor replacement were a major source of stress to parents. The child would often have to be held down and would be screaming whilst a doctor or nurse tried to insert the needle into the vein:

$\mathrm{FG}(2 \mathrm{f})$ : The whole thing is just a complete nightmare that you just don't imagine that you are ever going to have to do and all you want to do is pick your child up, love them, you don't want to see them in this pain but you have got to hold them down.

Trying to locate a vein was one of the worst aspects of these early years, making parents dread having to seek treatment:

Int(1f): The biggest impact is those preschool years on your life ... you see (the child) having needles, (doctors) trying to find veins, it is horrendous for a parent, it really is.

The difficulties parents experienced during these early years were often a catalyst for the parents deciding that they would learn to do the treatment themselves. Parents also realised that they had to begin to manage and cope with haemophilia:

$F G(2 f)$ : I could have gone to pieces in the beginning and gone, 'This is terrible and I just can't cope', and he (husband) said 'You can't do that, what about the child?', but he is quite right and you have to start dealing with it.

\section{Managing the condition}

This theme includes gaining knowledge of haemophilia, treatment of bleeds and prophylaxis and playing sport.

\section{Gaining knowledge of haemophilia}

The haemophilia centre staff were perceived by all the parents to be a valuable source of expertise to draw on, particularly in the early years. Parents felt that they really needed the professional support when the child was very young:

Int(3f): It was that particular time that we really felt we needed looking after because it was all scary, but as years have gone by ... it becomes much more part of your life.

Parents would often opt to travel to the haemophilia centre rather than attend a more local hospital or see their GP because of the expertise available. However because patients were reluctant to use local services, other health care professionals did not become educated about haemophilia and its current management. This means that outdated knowledge can be perpetuated, as identified by some of the parents when told about the initial diagnosis. 


\section{Treatment of bleeds and prophylaxis}

As the child became older (two to three years), the veins generally became more accessible and the parents could learn to do the injections themselves. However it took time and patience to develop the technical skills required to undertake the venepunctures. Once they could access the veins, the child could begin prophylactic treatment. Having prophylaxis also gave the family more freedom and the protection it provided increased parents' confidence to allow the child to undertake more vigorous activities. Prophylaxis was often seen as 'life changing' as it helped to reduce a lot of the concerns in the early years:

$\mathrm{FG}(2 \mathrm{f})$ : Once you get that control back and ... do your own treatment, you can work your life around it, then it is a lot easier.

However if they had difficulty accessing the veins, the problems could continue.

$\mathrm{FG}(4 \mathrm{f})$ : If the treatment is going well, life is fine ... but if you have got problems with treatment ... it rules your life, you are trapped.

However whilst the child and family were able to participate in more normal activities, some parents reported feeling restricted and overwhelmed by the responsibility of always needing to be available. They were 'on call' 24 hours a day in case factor replacement was needed:

Int(1f): You are the only person who can give the treatment. We always had to leave a contact number, we couldn't go anywhere.

However, when factor replacement was going well, haemophilia could be almost forgotten, it was such a normal part of life:

Int $(3 \mathrm{~m})$ : What I think about ... I wouldn't know how to live with boys without haemophilia, that would have been so odd

Parents built up experience in how to avoid and manage bleeds. Mothers, who often spent more time with the child, developed experience regarding how much activity her child could do and an intuitive knowledge of the condition and its management. The longer the period of time with no bleeds, the more confident the parent became. However that confidence could quickly be deflated if bleeds occurred and the unpredictability of the condition was again exposed. 
The child's acceptance of having the injection was an important issue for parents. Older children would usually comply whilst the factor replacement was being administered. This made the whole experience much less traumatic for all the family. The success of prophylaxis meant that some children experienced so few, if any, bleeds that they questioned whether they still needed it. One mother reported a conversation with her child who had said:

FG(2f): 'I haven't got haemophilia, I am all right'. Sometimes he has even said, 'I don't need this anymore, there is nothing wrong with me', and we have said, 'If you don't keep having it, there will be'.

This could lead to conflicts regarding suitable activities for the child.

\section{Playing sport}

Playing sport and deciding which sports were and were not suitable for children with haemophilia raised many dilemmas for parents. Sport embodies masculinity, culture and socialisation as well as the benefits of physical exercise (Park, 2000). Being able to compete in a sport with their peers was a tremendous boost to a haemophilic child's self esteem. The culture in the UK is to play football (soccer) both as a social leisure activity and within schools and clubs. However there is debate among health care professionals regarding whether this is an acceptable sport or not for individuals with haemophilia because of the risk of injury. Conflicting information between centres or professionals over the appropriateness of sports such as football could also contribute to parents' concerns. Parents often rationalised that playing football and kicking a ball was acceptable when the child was young. As one mother said:

Int(1f): So I didn't see any problem with him whilst he was at junior school kicking a ball around in the playground because for a little boy to sit on the sidelines... So we ran certain risks and he had the odd bleed but he could have had the odd bleed through doing nothing.

However, difficulties arose as the child grew up and the game became competitive and rougher. The child often had to stop playing football either because there was an increased likelihood of bleeds. These decisions were difficult for parents as over the years the child may have become quite skilled at the sport, often playing in a team. It was then more problematic for parents to have to stop an activity that their child enjoyed and was successful. Parents wanted the child to participate with others as much as possible and have opportunities to succeed and do well. Some parents allowed the child to continue playing contact sports and just hoped that no injury occurred. 


\section{Engaging with others}

This theme includes: potential to be isolated, trusting others, acting as an advocate, employment and the family.

\section{Potential to be isolated}

Parents acknowledged that they had to be able to deal with their own feelings and emotions and start to come to terms with their child having haemophilia before they felt able to discuss their child's problems with others. Some parents found it difficult to talk to family and friends or to deal with the reactions of other family members, particularly if they were feeling vulnerable themselves:

$F G(3 f)$ : I had no energy to deal with them (family) being scared, I couldn't deal with that.

Parents, because of their own loss of self esteem may avoid interactions with others and the increased isolation then emphasised their loss of self. Parents could also feel isolated by the increased care that was required for their child, which took time and effort away from social activities. Being isolated and maintaining secrecy may also help to avoid having to confront their own fears (Cohen, 1993). These feelings of isolation may be heightened by not trusting others to look after the child.

\section{Trusting others}

Parents recalled the difficulties of leaving their child with others and the additional responsibility imposed by having to look after a haemophilic child. Some parents were aware that they were more likely to invite other children to visit their home than the converse. If their child was invited out, parents were sometimes aware that certain games were not played. This could lead to parents feeling anger and frustration on behalf of the child. As one mother recalled:

Int(1f): R was one of his best friends and they hired a bouncy castle and didn't invite him - he could see all the children from the window ... I cry now over it.

With increasing experience of haemophilia and increased confidence, parents felt able to talk to others and also to allow others to look after their child: 
$F G(3 f)$ : What I feel great about is that now that I am a bit more in control of things I have been able to rely on my very close family and friends and now I am able to delegate things a bit more.

\section{The parent as an advocate}

In the child's early years, the parents tended to adopt a more passive role in their interaction with health care professionals. As they gained experience, they did not always agree with professionals' opinions and over time learnt to question and, with increasing experience, to challenge professional judgements if they felt that it was an issue that they did not agree with. They felt that they knew their child best and that was of paramount importance in the decisions that they had to make:

Int(1f): I have had rows (arguments) with doctors and come out and think it is my child, I will do what I want and because of the haemophilia that has made me like that because I don't have that much trust in doctors, not all of them ...

The knowledge parents gained about haemophilia gave them the confidence to deal with health professionals in ways that they would not have done otherwise. Parents also felt that they had to campaign for resources and be aware of what was happening both nationally and internationally in the management of haemophilia to ensure that their child was receiving the optimum care. Being 'on top of the situation' was also stressful and time consuming. A particular challenge for parents and children was that haemophilia was generally 'invisible' which paradoxically made it easier to keep secret but made it more difficult to explain to others. As the child reached teenage years, children became more aware of haemophilia and generally became more secretive about it. Parents were sensitive to their child's increasing concerns. As one father said:

$\mathrm{FG}(1 \mathrm{~m})$ : You are excruciatingly aware of the embarrassment factor for them, especially when they get a little bit older, so it is like a juggling act.

Parents reported having to spend considerable amounts of time planning for various life events, such as school or social activities that for other parents would be routine. Parents often had to assert their authority:

FG(3f): But even for that 20 minutes in the bus I had to arrange for emergency procedures to be put in place in case something happened to the bus driver, to the assistant. I spent a month in meetings explaining everything. 
Despite the support of haemophilia centre staff, parents still felt that for many routine activities that they had to challenge practices and make decisions about who to inform on behalf of their children. Parents wanted their children to have the same opportunities as other children but had to ensure that the risk of bleeds was recognised and the relevant people were informed

\section{Employment}

The requirement to be available to care for their child at any time often made it more difficult for some mothers to seek employment. Three of the mothers had had to give up work to care for their sons. The parents' work had to be flexible enough to be able to leave work immediately if required. If parents were experiencing difficulties in managing their child's haemophilia, often the job became unsustainable:

$F G(2 f)$ : I had a job last year for six months. I gave that up in the end because I just can't cope with it all ... it was a complete nightmare.

It appeared that these parents often faced attitudinal barriers to their working practices, with employers being inflexible to particular needs of these parents. Although some parents reported that their employers stated that they could leave work in an emergency to care for their child, in practice this was often difficult. As one mother reported:

$F G(3 f)$ : I just want to work in an environment which will support me, which is impossible. You just have to accept it.

\section{Family}

Having a child with haemophilia affected the entire family dynamics. Parents reported difficulties for siblings who often did not have the understanding that they needed to be more careful around the haemophilic child, especially if the child had a bleed. Parents had to teach other children how to behave appropriately without over protecting the haemophilic child.

Having to cancel activities if the child developed a bleed also impacted on the family. As siblings become more aware of how life was affected by having a child with haemophilia in the family, they too could feel frustrated even if previously they had been supportive of their brother: 
FG(2f): Now my daughter is getting older she will say things like, 'he has done his legs so we can't do this' ... she has never said anything before and now suddenly, she is exasperated by certain things that she had perhaps just learnt to live with.

These pressures on family life could put an added strain on the parent's relationship with their partner. This was often enhanced by the greater responsibility that usually the mother had for providing the additional care for the child. Fathers who were often away at work during the day did not always have the same level of experience and this could be a source of conflict between parents. Sometimes the family unit would break down. One of the participants had separated from his wife:

$F G(1 \mathrm{~m})$ : It was a huge, huge impact on us but we had an awful lot of deal with. It was an avalanche really ... we started having problems at home and we had huge rows (arguments) .... Yes it was massive, massive on our relationship.

Other partnerships appeared to be strengthened by having a child with haemophilia and as a result felt that the bond between them was stronger. However, parents described how they had had to work through the difficulties as they adapted to living with their child. As one said:

$F G(2 f)$ : We had to learn to communicate ... otherwise we wouldn't have lasted this long.

\section{Mastery}

This theme includes accepting the condition, developing mastery and threats to mastery.

\section{Accepting the condition}

Parents reported how living with a child with haemophilia became incorporated into the fabric of family life. Parents could administer factor replacement at home, the child was more able to explain what their problem was and the parents could reason with the child. Acceptance involves 'giving up attempts to change events that cannot be changed and making a decision to move forward' (Younger, 1991:85). As one father said:

$\mathrm{FG}(1 \mathrm{~m})$ : I have kind of come to a plateau with it ... I don't blame myself, I don't blame him, it is not anybody's fault. I really try and kind of look at it ... not in a positive way, but I am really trying not to get into that thing of being angry at it ... it just is there ... and we just deal with it. 
Over time, parents seemed to reconceptualise their values and expectations based on what their child could achieve. Recognising the achievements of the child in spite of difficulties could lead to positive experiences for parents:

$\mathrm{FG}(1 \mathrm{~m})$ : When it works the pay off is huge. When they achieve something because of the effort you put in, it is quite magical.

Another said:

$F G(3 f)$ : It gives you wings, the small things.

\section{Developing mastery}

Mastery embraces knowledge of the condition and the concepts of resilience and personal growth of an individual (Younger, 1991). Parents recognised that they developed as an individual as a result of their experiences.

$\mathrm{FG}(1 \mathrm{~m})$ : It has made me a bigger person in my character. You have to just grow up and realise the problem is bigger than you. You have to think differently ... You go to a deeper level having experienced very different situations.

Parents were aware that they needed to be resilient. They described having to develop a 'hard shell' to be able to deal with other people and the social world in which they lived. In times of difficulty they retreated to the security of the family unit and those who understood their life with haemophilia. They were aware that haemophilia had a big impact:

$F G(2 f)$ : It does put you in a different place, a very different place.

Some parents felt that the experiences had enabled them to be a 'better person':

$\mathrm{FG}(3 \mathrm{f})$ It has helped me to be a better human being ... I have no regrets about the life I used to have ... It is personal to me and the way I have evolved with (my son). It has helped me to grow out of wherever I was.

Managing the child with haemophilia could be rewarding if the child was experiencing few problems, one parent even describing these times as a 'golden period'. Experiencing very difficult situations could also generate a feeling of closeness to the child. As one father said:

Int(3f): It is almost ... you are so in tune with how they were and how they are physically. ... I was really aware of them and everything about them and it still feels 
like they are very, very close, physically very close, and they wouldn't have been without it. So I kind of think sometimes it is a bond in a sense.

\section{Threats to mastery}

Even if the parents were treating the child successfully, the child could still experience bleeds and that was a cause of stress for parents. Despite the improvements in the medical care and the obvious benefits of home treatment, parents still reported haemophilia as:

$\mathrm{FG}(2 \mathrm{f}):$.. a fragile disease ... and that is a shock and ... (it) can be quite overwhelming at times.

The child could look normal and be very active but an apparently minor injury could render the child immobile. The unpredictability and loss of control that could still impact on the parent's lives was an additional responsibility that could never be completely forgotten or ignored:

$\mathrm{FG}(1 \mathrm{~m})$ : It is a huge heavy burden of responsibility that you never feel you can let go of ... obviously you have periods when everything is fine and then it will happen again. So yes it has made me quite sort of tough emotionally.

As a result they sometimes needed an outlet for their emotions:

FG(2f): When I dropped him off at school and I have sat and cried all the way home, watching him go in on these crutches thinking, is he going to be all right? ... ... And I am thinking I don't want a disabled child. And I can't think like this, but your whole life is ... it is like somebody has scrapped everything off the top and it is just all raw

This suggests that whilst parents are able to demonstrate resilience and personal growth in dealing with haemophilia, their emotional wellbeing was vulnerable to the setbacks that their child may experience due to haemophilia.

\section{Discussion}

This qualitative study highlights the importance of evaluating the experiences of other family members as well as the individual who has the condition. Despite the improvements in the medical management of haemophilia in the last 10-15 years, the findings from this study suggest that parents' lives are transformed by having a child with haemophilia. Interestingly the medical model with its emphasis on 'adjusting' to the condition tends to focus on the individual concerned and the wider family network is ignored (Oliver, 1983). 
Finding out that that their child had haemophilia was an emotional shock and initially had a significant impact on the parent's self esteem. This response can be illustrated by Cohen's uncertainty model (Cohen, 1993). The parents' previously held knowledge, beliefs, values, expectations and daily life routines are challenged by the birth of the child with a health problem (Cohen, 1993). Their relationship with their partner and family and their lifestyle can all be threatened. This is made more difficult by the society in which they live, where health problems, particularly involving children are perceived as a tragedy (French and Swain, 2004).

The early years of the child's life are characterised by the parents feeling out of control, in a constant state of uncertainty and lacking in experience. The administration of factor replacement, which was often distressing for the child at the time, was also very stressful for the parent due to difficulties with venous access. Conflicting information between centres or professionals over the optimal management of haemophilia could also contribute to parents' concerns. Parents regarded this period of time as being 'out of control'. Other studies involving children with other health conditions have described the initial stages after the diagnosis as 'helpless floundering' when families are reported to be 'living in chaos' (Wuest and Stern, 1990:31). Not surprisingly, QoL at this time has been reported as poor (Wuest and Stern, 1990). The parents in this study sought to become knowledgeable about haemophilia to enable them to regain control and manage the uncertainty.

Strategies such as 'living for today', a common strategy when faced with adversity (Cohen, 1993), could lead to difficulties. Children may be more prepared to take physical risks and participate in sport as they have little musculoskeletal dysfunction and their joints feel normal; they often lack experience of the severe effects of bleeds and may also miss the early signs of bleeds. Participating in sport, especially football, is an important part of belonging to the culture and male identity. This adds to the parents' difficulties regarding whether a child should be excluded, especially when there are no visible or clinical signs of joint impairment.

The challenges imposed by haemophilia also impacted on how parents engaged with others. This was managed by keeping secrets, ignoring comments made by the general public and becoming assertive in their dealing with others. Parents have to respond and adapt to new situations as the child progressed through various developmental milestones. Parents were not only aware of their own experiences of 
difficulties of relating to others, but they also empathised with their child's difficulties very acutely.

Parents had to spend a considerable amount of time acting as an advocate for their child and ensuring that appropriate safety procedures were in place in order to avoid bleeds and injuries. All of these challenges could lead to conflicts between the parent and their partner and have a wider impact on the whole family network. It is common practice that mothers are more likely to be the main care provider and therefore develop expertise in managing their child's health problems (Gibson, 1995, Gallo and Knafl, 1998). The parent, commonly the mother, was the key player in trying to minimise the effects of haemophilia on the family and in managing the child's condition. The increased effort required to do this could be described as 'exhausting'.

Over time parents demonstrated mastery and acceptance of the condition but, depending on any problems that their child was currently experiencing, this appeared to be a 'fragile' situation. The parents made efforts to regain their self esteem by taking control and learning about haemophilia, normalising the management of the condition into family life, accepting what could not be changed, learning to trust others with the care of their child and re-evaluating their expectations. Teaching the child to accept the treatment has also been recognised as embracing normality (Anderson, 1981). Some of these adaptations become so routine and normal that they are less likely to be perceived as a problem. Interestingly, In the development of the Haemo-QoL, Bullinger et al. (2002) identified that while $32 \%$ of parents reported burden, stress and anxiety as a result of their child having haemophilia and a smaller percentage reported having to remain nearby, $20 \%$ perceived no problems. This may depend on the stage the parents have attained in their management of the condition and their success in managing the condition.

The parents' recognised their own personal self development and regarded themselves as more resilient in dealing with the emergence of new problems. The development of expertise and skills that they attained was important in their role as an advocate and in building their confidence. What also became apparent was that the parents enjoyed meeting other parents and the focus group provided a valuable support network and enabled parents to share experiences. 
Professionals evaluating QoL in this group may need to consider the age of the child and problems being experienced as this may have implications for the parents' QoL. There is also a need for further studies of the impact of haemophilia on parents QoL as well as other players, such as partners of those who have haemophilia, siblings and the wider social network including friends. Greater support, advocacy and counselling could be provided through haemophilia centres if specific issues are identified that need to be addressed.

\section{Trustworthiness}

This was an in-depth study of a small group of parents. Qualitative research methods promote the collection of rich data which must then be analysed and interpreted. Qualitative methods can be considered as 'soft data' and lacking in the exacting standardisation of quantitative methods, however the processes can still be thorough and rigorous thus ensuring the trustworthiness of the data (Berg, 2001). The credibility of the study was enhanced by ensuring that the transcripts were accurate, giving the participants an opportunity to verify the transcripts, reviewing interpretations of the analysis with the participants at subsequent focus groups and submitting transcripts to peers for their interpretations. The nature of qualitative data is such that it is not usually appropriate to generalise the findings beyond the group studied but the aim is to gain an understanding of the participants and their experiences through the analysis and interpretation of the data. The sample was self selected and may reflect parents facing particular circumstances. It is recognised that their perceptions may not be the same as other parents with haemophilia.

\section{Conclusion}

The findings of the discussions with 12 parents of children with severe haemophilia have been presented in four major themes. The parents initially have to come to terms with finding out about the diagnosis, which had a huge impact on them. They have to learn to recognise bleeds and to administer factor replacement. Parents also have to manage issues around who to tell, manage feelings of isolation and act as an advocate for their child. All of these issues could also impact on siblings and partners. Over time parents developed a number of strategies and re-evaluated their priorities in life. This involved personal self development. The initial difficulties improved with time, experience and the increasing age of the child as the parent reestablished control over their lives. In some cases the parents described the benefits of having a child with haemophilia. There was often a strong bond between parent and child, so that having haemophilia could be seen to be a positive experience. 
Parents' mastery could be threatened by new problems emerging, demonstrating the fragile nature of their resources and strategies. Parents may need ongoing professional support to assist them in their reconstruction of their life. More tolerance from society towards differences would also help to reduce the concerns of parents and their children. 


\section{References}

Agle, D., Gluck, H. \& Pierce, G. (1987) The risk of AIDS: Psychologic impact on the haemophilic population. General hospital Psychiatry, 9, 11-17.

Anderson, J. (1981) The social construction of illness experience: families with a chronically-ill child. Journal of Advanced Nursing, 6, 427-434.

Berg, B. (2001) Qualitative research methods for the social sciences, London, Allyn and Bacon.

Bullinger, M., Von Mackensen, S., Fischer, K., Khair, K., Petersen, C., RavensSieberer, U., Rocino, A., Sagnier, P., Tusell, J., Van Den Berg, H. \& Vicarot, M. (2002) Pilot testing of the 'Haemo-QoL' quality of life questionnaire for haemophiliac children in six European countries. Haemophilia, 8, 47-54.

Bullinger, M., Von Mackensen, S. \& Group, A. H.-Q. (2003) Quality of life in children and families with bleeding disorders. Journal of Pediatric Haematology and Oncology, 25, S64-S67.

Bury, M. (1982) Chronic Illness as biographical disruption. Sociology of Health and IIIness, 4, 67-81.

Buzzard, B. (1996) Sports and haemophilia. Clinical Orthopaedics and Related Research, 328, 25-29.

Canclini, M., Saviolo-Negrin, N., Zanon, E., Bertoletti, R., Dgirolami, A. \& Pagnan, A. (2003) Psychological aspects and coping in haemophilic patients: a case controlled study. Haemophilia, 9, 619-624.

Cohen, M. (1993) The unknown and the unknowable- managing sustained uncertainty. Western Journal of Nursing Research, 15, 77-96.

Crowley, C., Harre, R. \& Tagg, C. (2002) Qualitative research and computing: methodological issues and practices in using QSR NVivo and NUD*IST. International Journal of Social Research Methodology Theory and Practice, 5, 193-197.

French, S. \& Swain, J. (2004) Whose tragedy? Towards a personal non tragedy view of disability. In Swain, J., French S., Barnes, C. \& Thomas, C. (Eds.) Disabling barriers - enabling environments. 3rd ed. London, Sage Publications.

Gallo, A. \& Knafl, K. (1998) Parents' reports of 'Tricks of the Trade' for managing childhood chronic illness. Journal of Society for pediatric Nursing, 3, 93-100.

Gibson, C. (1995) The process of empowerment in mothers of chronically ill children. Journal of Advanced Nursing, 21, 1201-1210.

Manco-Johnson, M., Morrissey-Harding, G., Edelman-Lewis, B. \& Oster, G. (2004) Development and validation of a measure of disease specific quality of life in young children with haemophilia. Haemophilia, 10, 34-41. 
Miller, R., Sabin, C., Goldman, E., Clemente, C., Sadowski, H. \& C.A., L. (2000) Coping styles in families with haemophilia. Psychology, Health and Medicine, 5, 3-12.

Miller, W. \& Crabtree, B. (1999) The dance of interpretation. In Crabtree, B. \& Miller, W. (Eds.) Doing qualitative research. London, Sage.

Oliver, M. (1983) Social work with disabled people, London, MacMillan.

Park, J. (2000) 'The worst hassle is you can't play rugby' Haemophilia and masculinity in New Zealand. Current Anthropology, 41, 443-452.

Rice, P. \& Ezzy, D. (1999) Focus groups, Oxford, Oxford University Press.

Richards, T. \& Richards, L. (1998) Using computers in qualitative research. In Denzin, N. \& Lincoln, Y. (Eds.) Collecting and Interpreting Qualitative Methods. London, Sage Publications.

Salk, L., Hilgartner, M. \& Granich, B. (1972) The psycho-social impact of hemophilia on the patient and his family. Social Science and Medicine, 6, 491-505.

Schoenmakers, M., Gulmans, V., Helders, P. \& Van Den Berg, H. (2001) Motor performance and disability in Dutch children with haemophilia: a comparison with their healthy peers. Haemophilia, 7, 293-298.

Wuest, J. \& Stern, P. (1990) Childhood otitis media: the family's endless quest for relief. Issues in Comprehensive pediatric nursing, 13, 25-39.

Young, N., Bradley, C., Blanchette, V., Wakefield, C., Barnard, D., Wu, J. \& Mccusker, P. (2004) Development of a health-related quality of life measure for boys with haemophilia: the Canadian Haemophilia Outcomes - Kids Life Assessment Tool (CHO-KLAT). Haemophilia, 10, 34-43.

Younger, J. (1991) A theory of mastery. Advances in Nursing Science, 14, 76-89. 